\title{
Práticas de professores cribiás: representações sociais e formação docente
}

\author{
Las prácticas de los profesores de cribiás: las representaciones sociales y en la \\ formación docente
}

The practices of the teachers cribiás: social representations and teacher training

\author{
Daniela Barros da Silva Freire Andrade \\ Universidade Federal de Mato Grosso (UFMT), Cuiabá - MT/Brasil \\ ORCID: 0000-0002-7861-3814 \\ E-mail: freire.d02@gmail.com
}

Clécia Lino da Silva

Universidade Federal de Mato Grosso (UFMT), Cuiabá - MT/Brasil

ORCID: 0000-0002-7268-9711

E-mail: clecia_lino@hotmail.com

\begin{abstract}
Resumo
O presente trabalho analisa as representações sociais sobre práticas pedagógicas em contextos orientados para mudança do campo representacional de profissionais da educação, o processo de formação docente Cribiás, crianças sabidas. O referido projeto atua no sentido de difundir pressupostos da Teoria Histórico Cultural e da Pedagogia de Participação a fim de orientar práticas no contexto da educação infantil privilegiando processos narrativos autorais. Foram analisadas as representações sociais forjadas nos tensionamentos vivenciados ao longo do processo de formação do ano de 2019 . O estudo se caracteriza como de natureza qualitativa envolvendo 26 profissionais da educação, participantes do projeto. A produção de dados se deu em duas etapas, sendo a etapa 1, foco deste trabalho, caracterizada por respostas ao questionário de questões abertas, aplicado coletivamente ao final do processo formativo. Os dados, foram submetidos a análise inspirada na proposta de Núcleo de significação e revelam que o processo formativo mobilizou tensionamentos no campo representacional orientados para mudanças sobre as práticas pedagógicas na educação infantil. Tais mudanças afetam tanto a dimensão cognitiva, afetiva e atitudinal, podendo gerar impactos nas constituições identitárias das profissionais envolvidas.
\end{abstract}

Palavras-chaves: Representações sociais; Formação docente; Educação infantil.

\section{Resumen}

En el presente trabajo analiza las representaciones sociales acerca de las prácticas pedagógicas en relación con los contextos orientados al cambio en el campo representacional de los profesionales de la educación, en el proceso de formación de docentes Cribiás, los niños conocen. En el citado proyecto, se desempeña en la dirección de difusión de los supuestos de la Teoría Histórico Cultural, con el fin de orientar las prácticas, en el contexto de la educación de los niños. Se analizan las representaciones sociales forjadas en tensionamentos que se experimentan a lo largo del proceso de formación para el año 2019. El estudio se caracteriza por ser de naturaleza cualitativa, que implican el 26 de profesionales de la educación, los participantes del proyecto, los mismos respondieron a un cuestionario con preguntas abiertas, que se aplica de forma colectiva. Los datos fueron sometidos a análisis inspirados en la propuesta de la Bae de los significados y revelan que el proceso formativo movilizó tensiones en el campo representativo orientado a cambios en las prácticas pedagógicas de la educación en la primera infancia. Estos cambios afectan tanto las dimensiones cognitiva, afectiva $\mathrm{y}$ actitudinal, y pueden generar impactos en las constituciones de identidad de los profesionales involucrados.

Palabras clave: Representaciones sociales; Formación docente; Educación infantil.
Abstract
The present work describes the social representations on pedagogical practice as well as in contexts which are geared to changes in the field, keep in mind that for those who work in education, the process of teacher training Cribiás, wise children. The project works in order to 
publicize assumptions of the Historical-cultural Theory in order to guide practice in the context of early childhood education. They were examined for the social attitudes forged in the tensions experienced in the course of the process of the formation of the year by 2019 . The study is of a qualitative nature, involving 26 professionals from the education, the participants of the project, they answered a questionnaire with open-ended questions and was applied to groups. The data for the analysis were subjected to interpretative analysis, based on a proposal from the meaning core, reveal that the formative process mobilized tension in the representational field oriented to changes in pedagogical practices in the field of early childhood education. Such changes affect both the cognitive, affective and attitudinal dimension, and may impact the identity constitutions of the professionals involved.

Keywords: Social representations; Teacher training; Early childhood education.

\section{Introdução}

O presente estudo discute as representações sociais sobre práticas docentes em contextos promotores de mudança do campo representacional e propõe identificar e analisar os conteúdos representacionais sobre práticas pedagógicas de professores Cribiás Profissionais da educação envolvidos no projeto de formação profissional docente intitulado Cribiás, crianças sabidas ${ }^{1}$.

O referido projeto se desenvolve no âmbito da extensão universitária, em parceria com a rede pública de ensino, e se orienta no sentido de difundir os pressupostos da Teoria Histórico-Cultural (Vigotski, 2009; 2010), Pedagogia da Participação (Formosinho \& Oliveira-Formosinho, 2019) em articulação com a noção de espaço narrativo (Sennett, 1990) e com a expressão Educação Infantil como espaço narrativo $^{2}$ (Andrade, 2007).

Entende-se que o compartilhamento das representações sociais ancoradas no princípio da Pedagogia da Participação e na perspectiva Histórico-Cultural de Desenvolvimento Humano, no interior do processo formativo,

\footnotetext{
1 A expressão Cribiás foi construída no interior do projeto formativo pelos participantes envolvidos em exercício de licença poética. Trata-se da junção das palavras criança e sabiá, considerando a polissemia do termo sabiá, sabia, saber, sabida. A expressão deu nome ao projeto de formação permanente de docentes da Educação Infantil e primeiro ciclo do Ensino Fundamental da rede pública de ensino de Cuiabá. Tratase de ação colaborativa entre o Programa de PósGraduação em Educação, da Universidade Federal de Mato Grosso, campus Cuiabá - Grupo de Pesquisa em Psicologia da Infância, Curso de Psicologia (CP) e profissionais da Secretaria Municipal de Educação do mesmo município.
}

contribuem para o delineamento de um ambiente de pensamento propício para o estudo de múltiplos objetos relacionados às representações sociais sobre Educação Infantil, com impacto na constituição identitárias das profissionais.

O estudo dedica-se a analisar o compartilhamento e negociação de significados no contexto formativo e, para tanto, apoia-se nos pressupostos da Teoria das Representações Sociais. Ao compreender as representações sociais como saberes do senso comum organizado em torno de um conjunto de valores, atitudes, julgamentos e informações tem-se o contexto da formação de professores como um ambiente de pensamento (Moscovici, 2009) potencialmente capaz de impactar a subjetividade de professores, modos de ser e estar na profissão, e que de igual modo orienta novas práticas pedagógicas no âmbito da educação infantil.

Neste contexto, destacam-se as pesquisas sobre a Educação Infantil realizadas por Lorensini (2018) e Costa (2020) que

\footnotetext{
2 Pressuposto central da Proposta Pedagógica para a Educação Infantil de Cuiabá.
} 
desenvolveram seus estudos com a mesma população. Os referidos estudos analisam, o processo de compartilhamento da expressão Educação Infantil como espaço narrativo levando em consideração o fenômeno da resistência e não adesão aos novos conteúdos representacionais e a formação de grupo minoritário com maior adesão a proposição da Pedagogia de Participação (Formosinho \& Oliveira-Formosinho, 2019) em diálogo com a narrativa anunciada como modalidade discursiva.

A formação profissional docente compreendida na sua complexidade, envolve dimensões que vão para além do conhecimento técnico-científico, trata-se de uma multiplicidade de elementos como habilidades e valores, que se constituem no fluxo do pensamento científico e do senso comum, que atuam nas vivências individuais e coletivas ao longo da história de vida pessoal, acadêmica e profissional. Neste sentido, a formação docente é compreendida conforme as reflexões de García (1999 citado por Martins, Abdalla \& Silva, 2016) um continuum o que leva a noção de desenvolvimento profissional de professores com caráter contextual, organizacional e orientado para a mudança. No âmbito da perspectiva psicossocial, assumida pelo presente trabalho, serão privilegiados os estudos de Moscovici (1978, 2009), Jodelet (2001), Moliner (1996) e Marková (2017); Bauer e Gaskell (1999); Nóvoa (1995).

O contexto formativo, nesse sentido, é caracterizado como na sua íntima relação entre a teoria e prática e possui potencial para impactar a construção identitária dos docentes, visto que tensiona os paradigmas da pedagogia convencional/prescritiva com o da pedagogia da participação no qual o profissional em formação tem o exercício de repensar suas práticas e saberes socialmente construídos.

\section{As representações sociais como elementos constitutivos do processo de formação docente: orientação de práticas e processos identitários}

Martins, Abdalla e Silva (2016), em estudo que discute a relação entre formação docente e representações sociais, consideram que o desenvolvimento profissional de professores se relaciona aos termos profissionalização e profissionalidade. A profissionalização refere-se "ao modo pelo qual os profissionais afirmam o valor de seus serviços especializados a outros agentes sociais e ao ambiente social mais amplo" (p.37). Implica dizer que o mesmo é um processo socializador de constituição de características de uma profissão, orientado pela cooperação e pelo progresso social porque comprometido com a melhoria do desempenho do trabalho profissional.

Nessa perspectiva, a profissionalização permite pensar o professor como construtor de sua identidade profissional inserida em contextos específicos onde as mesmas são forjadas. Tais contextos são permeados por saberes e valores tomados como referências para a ação consciente do profissional.

Já a profissionalidade deve ser compreendida ao mesmo tempo como estado e processo. Esta, reúne as características de uma profissão, trata-se de racionalização de saberes e habilidades que orientam o exercício da profissão, saberes das disciplinas e saberes pedagógicos que orientam práticas e constituem competências profissionais. Profissionalidade de professores são características que distinguem a profissão docente, uma forma de ser e estar professor, o que delineia modos de agir, pensar e sentir característico da profissão - a profissão em ação.

A Profissionalidade leva em consideração comportamentos, destrezas, atitudes e valores, atributos socialmente construídos. Tal característica, a de ser socialmente referenciada, permite que a profissão seja distinguida dentre outras. No âmbito da profissionalidade, as autoras, apoiadas em Roldão (2005), dão ênfase para a dimensão do pertencimento a um coletivo no interior do qual ocorrem compartilhamentos de significados cuja ação regula e defende o 
exercício da função e do saber que legitima a profissão.

Deste modo, no interior dos grupos de pertença, considerando as dinâmicas comunicacionais, pode-se pensar que a formação de professores anuncia processos que podem forjar a cultura profissional e organizacional e, conforme Nóvoa (1995) analisa, tais processos podem constituir o novo na profissionalidade docente. Nesta breve introdução é possível destacar a ênfase nas dimensões transubjetiva, intersubjetiva e subjetiva que constitui a profissionalização e a profissionalidade.

A relação Eu-Outro (grupo, organização, cultura) torna-se desta forma uma instância da realidade de grande valor para a compreensão da formação e desenvolvimento profissional, neste caso, aplicado à docência. Tal constatação permite, ao mesmo tempo que justifica, a aproximação entre os estudos sobre formação docente e sobre representações sociais.

Jodelet (2001), entende por representações sociais: "Uma forma de conhecimento, socialmente elaborada e partilhada, com um objetivo prático, e que contribui para a construção de uma realidade comum a um conjunto social" (p. 22). As representações sociais, são saberes do senso comum que se constituem na relação com valores, atitudes, julgamentos e informações. As mesmas são elaboradas por grupos sociais e se referem a determinado objeto (objeto de representação), no caso específico deste estudo tem-se como objeto de representação as práticas pedagógicas na Educação Infantil.

Além de orientar os processos de comunicação, as representações sociais possuem funções tais como: orientação de práticas, construção de saberes, processos identitários e justificativas face a tomadas de decisão. Bauer (1995) ainda acrescenta a função de resistência para anunciar a possibilidade de determinados grupos ou subgrupos negarem o discurso de outros, tendo como motivo a defesa identitária.
Neste estudo destaca-se a análise da relação entre o compartilhamento dos conteúdos representacionais e a significação das práticas educacionais com possível impacto na constituição identitária dos docentes. Deste modo, acredita-se que, pela via dos processos de compartilhamento de representações sociais seja possível estudar aspectos dos processos constitutivos da profissionalização e da profissionalidade docente.

Para tanto será levado em consideração os processos formadores de representações sociais e a noção de focalização. Além disso, será considerado a contribuição de Bauer e Gaskell (1999) referente a noção de projeto representacional.

Segundo Moscovici (1978) ancoragem e objetivação são processos cognitivos formadores de representações sociais. $\mathrm{O}$ primeiro destina-se a nomear e classificar os objetos de representação apoiando-se no repertório cultural existente. $\mathrm{O}$ segundo, a objetivação, destina-se a transformar o conteúdo representacional em uma imagem, uma metáfora, por exemplo.

Em função da objetivação, a representação social atinge estabilidade e pregnância na cultura. Quando se tem uma representação em tais condições, a imagem fica solta na sociedade, é aceita como realidade convencional e passa a ter adesão grupal, grande número de pessoas a incorpora, tendo em vista o seu poder de comunicação direta e imediata.

A orientação moscoviciana parte de três condições preliminares para a aparição de uma representação social e Moliner (1996) acrescenta outras. Segundo o autor, a orientação moscoviciana indicou como condições de emergência das representações sociais a dispersão da informação referente ao objeto de representação, a posição do grupo frente ao objeto, isto é a focalização, a forma como o objeto é percebido pelo grupo e a pressão à inferência, traduzida pela necessidade dos indivíduos de desenvolver condutas e 
discursos coerentes sobre determinados objetos.

A dispersão de informações ocorre em função da complexidade do objeto social, constituindo uma espécie de barreira que impede os indivíduos de acessar as informações verdadeiramente úteis ao conhecimento do objeto. Essa dificuldade de acesso à informação favorece a transmissão indireta de saberes e a produção de distorções a respeito do objeto.

Com relação aos processos formativos pode-se pensar sobre a qualidade das estratégias de comunicação - metodologia - e ao acesso aos conteúdos, considerando-os tanto como produto, orientado segundo determinada perspectiva da Educação, como processo a ser reinterpretado pelos próprios docentes.

Ao considerar a limitação dos indivíduos em apreciar a complexidade do objeto, Moliner (1996) destaca a focalização como a segunda condição de emergência das representações sociais. A focalização refere-se à posição de determinados grupos que definem o interesse por certos aspectos de um objeto e, por conseguinte, o seu desinteresse com relação a outros, impedindo os indivíduos de terem uma visão global do objeto. Portanto, diferentes aspectos de um mesmo objeto chamam a atenção de diferentes grupos em graus diversos.

A focalização no âmbito dos processos de formação docente possibilita pensar sobre a existência de um filtro subjetivo, tanto grupal, quanto individual, que atua nos processos de comunicação e reelaboração dos conteúdos representacionais. De acordo com Marková (2017) "A maneira pela qual o ego seleciona aspectos da realidade é parcialmente determinada por sua experiência social, suas intenções, suas expectativas e sua compreensão da situação". (p. 370).

Tal fenômeno destaca a relevância do estudo sobre o impacto do sentimento de pertença dos atores sociais envolvidos bem como de seus marcadores sociodemográficos tais como formação inicial, gênero, orientação ideológica, atribuição funcional, apenas para citar alguns. Essa complexidade humana orienta tanto o acesso à informação, quanto os processos interpretativos relacionados à realidade, em adição, atuam no delineamento de processos identitários no interior dos grupos.

A terceira condição se relaciona à necessidade que os indivíduos sentem de desenvolver condutas e discursos coerentes a respeito de um objeto que mal conhecem. Frente ao desconhecido, os indivíduos deparam-se com zonas de incerteza de seu saber (Moliner, 1996), que são preenchidas por uma pressão à inferência. Sobre esse mecanismo, de pressão à inferência, vale lembrar Moscovici (2009) quando afirma que o que é anônimo não pode tornar imagem comunicável, ou ser facilmente ligado a outras imagens. Portanto, o inominável é relegado ao mundo da confusão e incerteza, tornando-se perturbador e rejeitado.

No âmbito da formação docente é possível pensar na atuação das dimensões intersubjetiva e subjetiva no processo de adesão aos conteúdos representacionais anunciados e compartilhados. Neste processo é importante considerar que todo grupo ou ator social se orienta para a preservação de sua identidade social e/ou pessoal, aspecto que mobiliza tanto a rejeição a novos conteúdos representacionais, quanto a adesão aos mesmos, uma vez que processos comprometidos com a mudança do pensamento social são vivenciados como ameaçadores porque remetem ao novo e, portanto, ao não familiar.

\section{Projeto representacional e dialogicidade: conceitos úteis para a formação docente}

Nóvoa (1995) ao analisar a formação docente destaca que este processo, para além de formar profissionais, produz uma profissão no sentido de reconhecer o potencial gerador de identidades sociais, saberes e práticas. Neste sentido, o autor caracteriza o processo formativo como espaço potencialmente sensível às mudanças. Para tanto, é preciso que proposições formativas superem a dicotomia dos saberes acadêmicos e saberes prático a 
favor de formatos que privilegiem formaçãoação e de formação-investigação.

A formação docente neste âmbito pode ser pensada como processo por meio do qual se forjam sentidos sobre a realidade no interior de grupos nômicos que operam como uma comunidade pensante e, como tal, compartilham representações sociais.

No âmbito das representações sociais, contribuem para a compreensão deste processo conceitos tais como projeto representacional, confiança interpsicológica, confiança e responsabilidade epistêmica.

Bauer e Gaskell (1999), ao proporem a noção de projeto representacional contribuem para pensar o processo de formação docente como uma vivência orientada para a mudança das representações sociais dos professores. A ideia de projeto representacional destaca a dinâmica do processo de compartilhamento dos conteúdos representacionais na perspectiva temporal. Neste sentido o conteúdo representacional compartilhado no tempo presente só é possível porque o mesmo está ancorado em conteúdo anteriormente constituídos e compartilhados no passado. No tensionamento e nas contradições inerentes ao processo de partilha e construção do pensamento social por atores sociais e seus grupos tem-se tanto processos de adesão, quanto de rejeição a perspectiva anunciada.

Assim sendo, pode-se dizer que todo processo formativo se estabelece na mediação

\footnotetext{
${ }^{3} \mathrm{O}$ referido projeto começou a ser delineado a partir de 2009 com a inserção de estagiários do Curso de Psicologia nas unidades de Educação Infantil em trabalho colaborativo junto as técnicas de desenvolvimento infantil (TDI). Em 2015, a modalidade Seminário Temático, disciplina do PPGE inaugurou-se a formação docente voltada para assessoras e coordenadoras pedagógica, professoras e TDIs cujas unidades de trabalho eram campos de estágio. Tal critério tinha como objetivo a formação de uma rede de colaboração técnica e científica triangulando universidade, assessoria pedagógica e profissionais da Educação que atuam diretamente junto às crianças e suas famílias. No fluxo desse processo, em 2016 o grupo atuante no Seminário Temático nomeou o processo formativo de Cribiás, crianças sabidas.
}

com um projeto representacional que, ao ser anunciado no presente revela seus processos de ancoragem em conteúdos historicamente forjados, mas também, revela pressupostos que delineiam a construção da realidade, prospectivamente.

Por sua vez, Marková (2017), ao analisar as comunicações sociais no contexto formativo destaca as noções de confiança interpessoal e epistêmica que tal mudança está alicerçada na dialogicidade constituída a partir da confiança na relação Eu-Outro.

A construção de uma realidade pautada no novo por um grupo social está, segundo Marková (2017) atrelada ao estabelecimento de relações de confiança interpessoal entre os envolvidos, aspecto que prescinde de comunicação horizontalizada. A partir desta, é possível que os atores sociais estabeleçam a confiança epistêmica no informante ou formador.

De modo a caracterizar o lócus do presente estudo, pode-se dizer que o projeto Cribiás, crianças sabidas $^{3}$, inspira-se na proposição de Nóvoa (1995) na qual formaçãoação e formação-investigação constituem elementos indissociáveis.

No âmbito da investigação pergunta-se: em que medida o ambiente de pensamento, forjado no interior do projeto Cribiás, impacta no campo representacional do grupo de professores envolvidos? E, neste processo, como se dá a significação de determinados 
objetos de representação que compõem o âmbito da representação social sobre a Educação Infantil? Para tanto, é útil anunciar que o principal pressuposto do projeto se refere a expressão Educação Infantil como espaço narrativo, marco presente na Proposta Pedagógica para a Educação Infantil de Cuiabá e mantida na revisão do documento realizada em 2019.

Conforme Andrade (2007, pp.102-103), o conceito de espaço narrativo:

[...] configura espaços que narram uma ficção para fazer com que o lugar tenha um sentido e um caráter, constituindo a personificação de um lugar. Pode ser entendido como um espaço aberto para desenvolver atividades imprevisíveis de eventos, e para criar uma história que pode ser objeto de interpretação ou ponto de partida para outras histórias. Contrapõe-se a qualquer outro tipo de espaço que permite apenas uma possibilidade de uso, ou melhor, a repetição de sequência de atos previsíveis préestabelecidos, tal qual uma linha de montagem industrial.

Envolve o trabalho prático de se produzir uma ficção, inventando um cenário que não se explica por si mesmo e que, para ser compreendido, requer informação. Nesse sentido, espaço narrativo é um lugar falado, que fornece a emergência do incerto e das possibilidades criativas presentes na noção de potencial de começos. Possui um caráter dramático, novelístico, que se desenvolve através de dispositivos de resistência, presentes no encontro com o diferente, tal como uma fronteira que demarca ao mesmo tempo diferentes territórios e o seu encontro.

No interior do projeto Cribiás, crianças sabidas, a noção espaço narrativo (Sennett, 1990) dialoga com a Psicologia do Desenvolvimento na perspectiva da Teoria Histórico - Cultural, a Sociologia da Infância (Sarmento, 2007), a Pedagogia de Participação e com os princípios da Educação Patrimonial. Neste contexto pode-se caracterizar o esforço de se pensar a Educação Infantil como um projeto cultural para a infância (Lorensini, 2018).

Os valores anunciados no interior do projeto destacam a Educação na perspectiva dialógica (confiança interpessoal e epistêmica $)^{4}$, os processos autorais de adultos e crianças, imaginação e sensibilidade estética, pertencimento cultural e comunitário.

Deste modo, o projeto de formação de professores Cribiás, crianças sabidas se configura como um fórum de produção de sentidos sobre as práticas docentes para a Educação Infantil e anos iniciais do Ensino Fundamental orientado para a mudança desta realidade por meio do compartilhamento de representações sociais ancoradas em pressupostos teóricos-metodológicos específicos.

A caracterização do projeto de formação de professores no contexto deste artigo presta-se a oferecer ao leitor elementos do projeto representacional cujos significados foram compartilhados e por sua vez, tensionaram o campo representacional dos docentes envolvidos.

\section{Procedimentos metodológicos}

\footnotetext{
${ }^{4}$ Marková (2017)
} 
De natureza qualitativa, esse estudo ${ }^{5}$ envolveu 26 profissionais da educação, participantes do projeto de formação docente Cribiás, crianças sabidas no ano de 2019. O referido projeto (2014-2019) orienta-se pela expressão Educação Infantil como espaço narrativo (Andrade, 2007) que se concretiza por meio da articulação entre os princípios da Pedagogia da Participação e da Educação Patrimonial. O projeto adota metodologia dialógica e vivencial por meio da qual difunde a importância da participação das crianças nas práticas educativas, via diálogo intergeracional (narrativas autorais de adultos e crianças), considerando seus pertencimentos comunitário e cultural nos processos de aprendizagem e desenvolvimento.

O processo formativo no ano de 2019 totalizou nove encontros distribuídos em oito meses, com duração de quatro horas cada, em diferentes contextos formativos, envolvendo exposição de Arte e laboratórios de construção de projetos, sua implantação e socialização de resultados.

Metodologicamente,

pode-se reconhecer que o estudo de caso ora apresentado se orientou pelos princípios da pesquisa participante (André, 2013) os quais permitem envolvimento no grupo pesquisado de maneira mútua e compromissada, articulando a observação e entrevistas de respondentes, com aprofundamento nas vivências da situação pesquisada.

Deste modo, o plano de produção e análise dados pode ser assim anunciado:

${ }^{5} \mathrm{O}$ estudo insere-se na intersecção entre o projeto de extensão Rede de apoio à Infância: interfaces com a Psicologia e Pedagogia e o projeto de pesquisa $A$ Construção do conhecimento social pelas crianças: estudo sobre vivências e significações infantis, ambos respectivamente registrados na Pró-reitora de Cultura, Extensão e Vivência e na Pró-reitora de Pesquisa da Universidade Federal de Mato Grosso e obedece aos procedimentos éticos exigidos pelo conselho de ética em pesquisa, sendo Termo de Consentimento Livre e Esclarecido, devidamente aplicado nos procedimentos de produção de dados.
Fase 1: questionário com questões semi-abertas, aplicado coletivamente, cujo enunciado convidava as participantes a escrever uma carta para uma colega recémchegada na cidade a procura de informações sobre projetos dedicados a formação docente, incluindo o projeto Cribiás, crianças sabidas. Ao longo da carta os respondentes deveriam falar sobre a relação do processo formativo e sua prática pedagógica e produzir metáforas segundo a técnica de indução de metáfora (Andrade, 2007) assim anunciada: Enfim colega, fazer parte do Projeto Cribiás é como se...?

Fase 2: entrevista semiestruturada realizada com três participantes.

Para efeitos deste artigo serão discutidos os dados da fase 1. As respostas foram submetidas a análise interpretativa inspirada na proposta de Núcleo de significações (Aguiar \& Ozella, 2006), segundo a qual após várias leituras flutuantes do material transcrito elenca-se os pré-indicadores que se aglutinam em indicadores e conteúdos temáticos os quais, por conseguinte, são sistematizados por intermédio dos núcleos de significação.

\section{Resultados e Discussão}

A partir dos dados levantados e analisados pela técnica núcleos de significação, foram encontrados três núcleos de significação advindos das falas das profissionais envolvidas no Projeto Cribiás. Respectivamente os núcleos foram organizados e assim nomeados: 1. Ouvir as crianças: entre tensionamentos e a agência da criança; 2. O Projeto Cribiás: 
capacitação e agenciamento de professoras; $\underline{3 .}$ O projeto Cribiás como atuante na promoção do bem estar docente.

\section{Núcleo de significação 1 - Ouvir as crianças: entre tensionamentos e a agência da criança.}

Neste núcleo destacam-se elementos associados a representação social de criança partilhada no contexto formativo. A análise dos excertos revela a associação da imagem de criança como atores, protagonistas, seres pensantes e sujeitos de fala.

O projeto, com as práticas nas escolas proporcionou aos alunos(as) muito mais oportunidades de serem protagonistas do seu processo de aprendizagem. $(\mathrm{P} 3){ }^{6}$

Ao colocar o projeto em prática com as crianças, me apaixonei por ver o quanto elas podem ensinar e o quanto são capazes. (P4);

Ouvir o que a criança tem a dizer, torna as ações diferenciadas. (P5);

Tirei a venda dos meus olhos e passei a ver as crianças como seres pensantes, como protagonistas. (P16.);

[...] Não é fácil, pois, as orientações e estudos do Cribiás vem contradizendo tudo que estudamos em nossas formações, mas é somente mergulhando de corpo e alma no projeto, você perceberá que as protagonistas são as crianças e que elas têm muito a nos falar. (P17);

Não tem mais como trabalhar as ações pedagógicas diferente, pois aprendi a oportunizar os meus alunos a serem autorais e protagonista da sua história. (P12).
Ao aderirem a representação de criança como sujeitos autorais e protagonistas os profissionais da educação anunciam as crianças como participantes na construção e efetivação das práticas pedagógicas, em uma relação que é dialógica e simétrica. Neste sentido, se aproximam da perspectiva da pedagogia em participação e revelam impactos na constituição identitária docente: "Tirei a venda dos meus olhos e passei a ver as crianças como seres pensantes[...]" (P16).

No processo de ensino e aprendizagem, segundo Marková (2017), existe a importância de que a confiança epistêmica esteja presente, pois possibilita engajamento, disposição e comprometimento tanto do professor/a como do aluno/a, e essa confiança entre ambos são dependentes. A confiança epistêmica entre aluno/a-professor/a, constituída por uma relação simétrica e horizontal manifesta reciprocidade, autonomia, criatividade e inovação. "Muitas vezes a gente não percebe, porque a gente impõe, a gente como professora a gente impõe tudo e quer uma resposta pronta, e não é assim." (P1).

No entanto, existem tensionamentos e estranhamentos ao considerar a criança como protagonista - conteúdo novo e não familiar. Tal representação contradiz conteúdos ancorados nas práticas tradicionais de ensino, uma pedagogia prescritiva, fortemente presente na memória coletiva. Nesta, o professor é o ator social majoritariamente ativo na relação com a criança, sua função consiste em transmitir conhecimento e a criança é representada como receptora e reprodutora de informações, como se pode notar no seguinte excerto: "[...]não é fácil, pois, as orientações e estudos do Cribiás vem contradizendo tudo que estudamos em nossas formações[...].” (P17). As profissionais revelam suas dificuldades em representar a criança enquanto sujeito ativo na construção de práticas pedagógicas, pois são vistas enquanto uma figura docente sem controle pelos seus pares.

\footnotetext{
${ }^{6} \mathrm{P} 3$ se refere à profissional número três e assim respectivamente
} 
Eu falava não, não é perder o controle, é deixar a criança se expor, é deixar a criança ser criança, e nós professores não deixamos, porque ele tem que ficar sentadinho, na cadeira enquanto eu falo e ele não pode se movimentar e fazer barulho. (P1).

Segundo Moscovici (2009) a não familiaridade intriga, incomoda e ameaça as pessoas, causando estranhamento. Mas vale ressaltar que nesses tensionamentos os processos identitários do ser professora é também construído e intensificado, pois o professor passa a pensar e questionar suas práticas, levando a uma ressignificação do ser professor.

O compartilhamento se constitui em uma dinâmica na qual se revezam sentimentos ameaçadores diante do novo e movimentos de abertura, tal como o anunciado pela metáfora "Tirei a venda dos meus olhos[...]" (P16).

\section{Núcleo de significação 2 - O projeto Cribiás: capacitação e agenciamento de professoras}

O segundo núcleo de significação revela que o protagonismo e processos autorais são anunciados para além da representação social de criança. Tais conteúdos também atuam como pontos de ancoragem na representação social de professor(a) compartilhada pelo grupo.

O projeto nos instiga a estudar cada dia mais. (P11);

As experiências que vivenciamos agregam muito em minha formação enquanto pessoa e profissional. (P14);

Ampliou minha visão, tenho um olhar mais sensivel voltado às nossas crianças e me sinto muito mais capacitada para trabalhar com a educação infantil. (P1);

A minha prática pedagógica deu um vôo que jamais imaginei em ter, pois através desse projeto, me instigou a ser cada vez mais pesquisadora. (P13);

Na minha prática pedagógica hoje, com as experiências adquiridas no projeto, dinamizou de tal forma que até as crianças já não se vêm sem essa vivência. (P15).

A metáfora associada ao olhar, anunciada no excerto presente no primeiro núcleo (P16) surge novamente no segundo núcleo desta feita por meio da resposta de outra professora: "Ampliou minha visão, tenho um olhar mais sensivel voltado às nossas crianças [...]" (P1). Outra metáfora utilizada é a de vôo tal como se pode observar: "A minha prática pedagógica deu um vôo que jamais imaginei em ter [...]” (P13).

Na pedagogia participativa, a criança é vista enquanto sujeito de direitos, que tem o poder de agenciar suas experiências, tendo autonomia de construir juntamente com o/a professor/a práticas pedagógicas que podem mediar sua própria aprendizagem. A concepção de criança é ancorada e objetivada na criançapessoa, que seria a imagem de criança como uma pessoa, "como um ser com agência e autonomia" (Oliveira-Formosinho \& Formosinho, 2017, p. 119).

$O$ relacionamento se estreita entre professor e aluno, você passa dessa barreira de que eu sou o detentor do conhecimento e você é pequenininho e por isso você me ouve, aprende e só! Você cria vínculo e ao criar vínculo, a criança aprende com uma facilidade muito maior, é uma pessoa que confia em mim e eu confio nela. (P1).

Pressupostos como estudo, pesquisa, e novas práticas pedagógicas são anunciados como elementos que impactam tanto na formação pessoal, quanto na formação profissional: "As experiências que vivenciamos agregam muito em minha formação enquanto pessoa e profissional" (P14). 
Em outro sentido, tais pressupostos também impactam a relação professoracrianças de modo que a profissional entende que: "[...] as experiências adquiridas no projeto, dinamizou de tal forma que até as crianças já não se vêm sem essa vivência." (P15).

As análises das profissionais envolvidos no projeto sugerem adesão aos princípios da Sociologia da Infância e a Pedagogia de Participação e revela a compreensão da dialogicidade na cena educacional.

\section{Núcleo de significação 3 - O projeto Cribiás como atuante na promoção do bem estar docente}

No terceiro núcleo de significação notase o compartilhamento de sentido que trata da dimensão afetiva do trabalho docente e do processo de formação.

É como se vivesse em um mundo
encantado, não no sentido de utopia,
mas de saber que não estou sozinha,
na buscar pelo
reconhecimento/valorização r da
infância. (P18);

Socializamos anseios, angústias e experiências com profissionais de várias unidades da rede municipal de Cuiabá. (P15);

As ações pedagógicas passam a ter leveza, não é saturada, nem cansativa. (P13).

A metáfora utilizada para descrever o processo formativo é "mundo encantado" para anunciar o sentido de fórum solidário e sentimento de pertença com clara repercussão no processo identitário como sugere o excerto: "É como se vivesse em um mundo encantado, não no sentido de utopia, mas de saber que não estou sozinha, na busca pelo reconhecimento/valorização da infância." (P18).

Os sentidos atribuídos à prática pedagógica estão ancorados nos princípios difundidos no projeto de formação e, a análise da profissional revelam que tais práticas são fontes de prazer e realização profissional: " $A s$ ações pedagógicas passam a ter leveza, não é saturada, nem cansativa." (P13).

O projeto Cribiás, crianças sabidas é anunciado como atuante na promoção do bemestar docente, visto que compartilham seus questionamentos em grupo, com autenticidade e cooperação entre as profissionais, em que relatam não se sentirem sozinhas, mas que pertencem a um grupo onde possam resolver problemas comuns e que as levam ao desenvolvimento não apenas profissional, mas também pessoal. Tal constatação referenda os preceitos de Marková (2017) sobre a importância da confiança interpessoal como condição para o estabelecimento da confiança epistêmica.

Cabe ressaltar que a metodologia adotada pelo projeto Cribiás, com orientação a prática dialógica e participativa, na qual difere de práticas hegemônicas pautadas no tradicionalismo da educação, atuou na promoção de um ambiente de pensamento intergrupal entre pares suscitando sentimentos de pertença, na qual supera o discurso de solidão profissional existente; promove $\mathrm{o}$ agenciamento de professoras e de crianças; ressignificação da identidade docente pautada na relação de interdependência da dialogicidade e confiança epistêmica; assim como, as profissionais anunciam a cumplicidade na íntima relação intragrupal com o ambiente formativo e seus pares, possuindo objetivos em comum na busca pela valorização da infância.

Contribuem para tais constatações os seguintes aspectos: 1 . A metodologia dialógica e vivencial aproximando teoria e prática no contexto da formação docente; 2 . A qualidade das relações vivenciadas no interior do processo formativo orientada pela horizontalidade nas relações de poder envolvendo especialistas, acadêmicos, professoras, coordenadoras e assessoras pedagógicas; 3 . O encorajamento de processos autorais das profissionais envolvidas; 4. As 
vivências dialógicas entre profissionais e crianças inspiradas nos processos autorais de ambos atores sociais e 5. Pertencimento cultural e comunitário de crianças e adultos

Com relação à prática pedagógica, é possível observar mudanças no campo representacional e nas práticas pedagógicas pelas professoras Cribiás e a formação docente como um ambiente de pensamento que permite reconstruções identitárias docente, pois o/a profissional se constrói no processo formativo ao mesmo tempo que o modifica.

\section{Considerações Finais}

Ao tomar a análise dos três núcleos de significação, permite-se pensar que o projeto de formação docente Cribiás, crianças sabidas têm possibilitado:

1. Uma dinâmica de compartilhamento de novos conteúdos sobre a prática pedagógica, inspirada no projeto representacional Educação Infantil como espaço narrativo, principal pressuposto da Proposta Pedagógica da Educação Infantil de Cuiabá. A mesma mostra-se alinhada a noção de confiança interpessoal e epistêmica, caracterizando o grupo de trabalho (profissionais da Educação, professores, graduandos do Curso de Psicologia e Pós-Graduandos do Programa de Pós-Graduação em Educação) como um fórum identificado com a produção de novos sentidos sobre a prática docente no contexto da educação coletiva de crianças. Este contexto tem possibilitado o debate das contradições das vivências pedagógicas sem com isso fomentar processos ameaçadores e de desaprovação, em seu lugar apresenta-se um convite à reflexão;

2. Os conteúdos representacionais compartilhados dizem respeito a representação de criança, professor e prática pedagógica. Com relação a representação de criança e de professor observa-se a referência ao protagonismo e aos processos autorais reafirmando a íntima relação Eu-Outro. Já com relação à prática pedagógica, delineia-se adesão aos princípios da pedagogia de participação considerando a criança como fonte de influência social capaz de inspirar o planejamento docente e transformar a vivência educacional em algo prazeroso. $\mathrm{O}$ debate sobre o tensionamento do campo representacional tem contribuído para a desnaturalização dos discursos hegemônicos que historicamente orientam práticas pedagógicas;

3. As profissionais consultadas revelam que o processo representacional, forjado no interior das trocas sociais do projeto de formação Cribiás, crianças sabidas, apresenta potencial para impactar na constituição identitárias das mesmas, mobilizando sentimento de pertencimento e competência profissional. Chama a atenção o discurso sobre solidão profissional sendo superada com a inserção das professoras em um grupo orientado pelo mesmo propósito - reconhecimento e valorização da infância, por consequência da própria profissão;

4. As metáforas, espontaneamente evocadas, revelam a objetivação das professoras participantes do processo formativo. Estas anunciam uma sensação de tirar as vendas dos olhos $\mathrm{e}$ de voar mais alto de modo a sugerir indícios de mudanças no modo de interpretar a prática pedagógica, as crianças e a si mesmo.

De uma forma geral, pode-se dizer que a aproximação das categorias teóricas relativas a Teoria das Representações Sociais mostraram-se adequadas ao estudo dos processo de formação docente na perspectiva dialógica tendo em vista que a dinâmica das trocas simbólicas são forjadas de forma horizontal, ou pelo menos, o tanto quanto possível. Tal característica potencializa a ação 
coletiva aproximando-a da atuação de um grupo nômico, aquele que é capaz de exercer influência em um entorno social tendo em vista a manutenção de debates e discussões sobre os mesmos pressupostos à medida que sustenta um ponto de vista coerente e normas próprias.

\section{Referências}

Aguiar, W. M. J., \& Ozella, S. (2006). Núcleos de significação como instrumento para a apreensão da constituição dos sentidos. Psicologia: ciência e profissão, 26(2), 222-245. Recuperado de https://www.scielo.br/scielo.php?pid=S141 4-98932006000200006\&script=sci_arttext

Andrade, D. B. F. (2007). A criança na educação infantil: por entre Emílias e Chapeuzinhos. Revista de Educação Pública, 16(31), 97-104. Recuperado de http://www.periodicoscientificos.ufmt.br/oj s/index.php/educacaopublica/article/view/5 $\underline{188}$

André, M. (2013). Etnografia da prática escolar. São Paulo: Papirus editora.

Bauer, M. (1995). A popularização da ciência como imunização cultural a função de resistência das Representações Sociais. In P. Guareschi, \& S. Jovchelovitch (Orgs.), Textos em Representações Sociais (183-209). Rio de Janeiro: Editora Vozes.

Bauer, M. W., \& Gaskell, G. (1999). Towards a paradigm for research on social representations. Journal for the theory of social behaviour, 29(2), 163-186. doi: 10.1111/1468-5914.00096

Costa, A. C. L. (2020). A formação docente no Projeto Cribiás, crianças sabidas segundo as profissionais da Educação Infantil de Cuiabá-MT: um estudo em representações sociais (Dissertação de Mestrado). Programa de Pós Graduação em Educação, Universidade Federal de Mato Grosso, Cuiabá.

Formosinho, J., \& Oliveira-Formosinho, J (2019). Pedagogias transmissivas e pedagogias participativas na escola de massas. In J. Formosinho, Documentação pedagógica e avaliação na educação infantil: um caminho para a transformação (pp. 3-25). Porto Alegre: Penso.
Jodelet, D. (2001). Representações sociais: um domínio em expansão. In D. Jodelet (Ed.), As representações sociais (pp. 31-61, T. B. Mazzotti, trad.). Rio de Janeiro: EDURJ.

Lorensini, S. R. G. (2018). Educação infantil na rede pública de Cuiabá: análise da construção de um projeto cultural para as crianças de até 3 anos, ambiguidades do percurso (Tese de Doutorado). Programa de Pós Graduação em Educação, Universidade Federal de Mato Grosso, Cuiabá.

Martins, M. A. R., Abdalla, M. F. B., \& Silva, A. F. L. (2016). Formação e profissionalidade docente: representações sociais de professores especialistas. In A. Novaes, V. L. Bôas, T. R. Ens (Eds.), Formação e trabalho docente: relações pedagógicas e profissionalidade-pesquisas com a técnica (33-62). Curitiba/São Paulo: PUCPRESS/FCC.

Marková, I. (2017). Mente dialógica: senso comum e ética. Curitiba: Pucpress.

Moliner, P. (1996). Images et représentations sociales: De la théorie des représentations à l'étude des

images sociales (Vol. 12). PUG.

Moscovici, S. (1978). A representação social da psicanálise (Á. Cabral, trad.). Rio de Janeiro: Zahar.

Moscovici, S. (2009). Representações sociais: investigações em psicologia social. Petrópolis, RJ: Editora Vozes.

Nóvoa, A. (1995). Vida de professores. Porto: Porto Editora.

Oliveira-Formosinho, J., \& Formosinho, J. (2017). Pedagogia-em-Participação: a documentação pedagógica no âmago da instituição dos direitos da criança no cotidiano. Em Aberto, 30(100). Recuperado de

http://rbep.inep.gov.br/ojs3/index.php/emab erto/article/view/3218 
Roldão, M. C. (2005). Profissionalidade docente em análise-especificidades dos ensinos superior e não superior. Nuances: estudos sobre educação, 12(13).

Recuperado de https://revista.fct.unesp.br/index.php/Nuanc es/article/view/1692

Sarmento, M. J. (2007). Visibilidade social e estudo da infância. In V. M. R.

Vasconcellos \& M. J. Sarmento (Orgs.), Infância (In)Visível (25-49). Araraquara: Junqueira \& Marin Editores.
Sennett, R. (1990). The Conscience of the Eye: The design and social life of cities. New York: WW Norton \& Co.

Vigotski, L. S. (2009). Imaginação e criação na infância. São Paulo: Ática.

Vigotski, L. S. (2010). A questão do meio na pedologia (MP Vinha, trad.). Psicologia USP, 21(4), 681-701. Recuperado de https://core.ac.uk/download/pdf/268308283 .pdf

\section{Dados sobre as autoras:}

- Daniela Barros da Silva Freire Andrade: Doutora em Educação. Psicologia da Educação pela PUCSP. Professora Titular do Programa de Pós-Graduação em Educação da Universidade Federal do Mato Grosso (UFMT) campus Cuiabá - MT. Telefone de contato (65) 3615- 8482, sala 40b, Instituto de Educação. Pesquisadora Associada da Fundação Carlos Chagas, participando do CIERS-Ed (Centro Internacional em Representações Sociais e Subjetividade Educação. Coordenadora do Grupo de Pesquisa em Psicologia da Infância (GPPIN).

- Clécia Lino da Silva: Acadêmica do Curso de Psicologia da Universidade Federal de Mato Grosso, campus Cuiabá, bolsista PIBIC/CNPQ no Grupo de Pesquisa em Psicologia da Infância - GPPIN.

\section{Agências de fomento:}

- Conselho Nacional de Desenvolvimento Científico e Tecnológico.

\footnotetext{
Declaração de Direito Autoral

A submissão de originais para este periódico implica na transferência, pelos autores, dos direitos de publicação impressa e digital. Os direitos autorais para os artigos publicados são do autor, com direitos do periódico sobre a primeira publicação. Os autores somente poderão utilizar os mesmos resultados em outras publicações indicando claramente este periódico como o meio da publicação original. Em virtude de sermos um periódico de acesso aberto, permite-se o uso gratuito dos artigos em aplicações educacionais e científicas desde que citada a fonte conforme a licença CC-BY da Creative Commons.
} 